\title{
Welcoming with risk classification in teaching hospitals: assessment of structure, process and result
}

\author{
Dagmar Willamowius Vituri ${ }^{1}$ \\ Kelly Cristina Inoue ${ }^{2}$ \\ José Aparecido Bellucci Júnior ${ }^{3}$ \\ Carlos Aparecido de Oliveira ${ }^{4}$ \\ Robson Marcelo Rossi ${ }^{5}$ \\ Laura Misue Matsuda ${ }^{6}$
}

Objective: to assess, from the worker's viewpoint, the structure, the process and the results of the Emergency Hospital Services that have taken up the guideline of "Welcoming with Risk Classification" in two teaching hospitals of the state of Paraná. Method: quantitative and descriptive research, exploratory and prospective, using random sampling stratified by professional category, comprising a universe of 216 professional people. Results: they found some points of agreement regarding the promotion of a welcoming and humane environment; privacy and security; welcome and shelter of the companion and also the sheltering and classification of all patients; however, there was disagreement about the comfort of the environment, reference system and counter-reference, prioritisation of seriously ill patients in post-classification service, communication between the members of the multi-professional team and reassessment of the guideline. Conclusion: the workers assess the development of the guideline as being precarious, due mainly to the lack of physical structure, due to the lack of physical structure and shortcomings in the service process.

Descriptors: User Embracement; Humanization of Assistance; Hospital Care; Triage.

\footnotetext{
${ }^{1}$ Doctoral student, Escola de Enfermagem de Ribeirão Preto, Universidade de São Paulo, WHO Collaborating Centre for Nursing Research Development, Ribeirão Preto, SP, Brazil. RN, Hospital Universitário de Londrina, Londrina, PR, Brazil.

${ }^{2}$ Doctoral student, Universidade Estadual de Maringá, Maringá, PR, Brazil. Assistant Professor, Faculdade Ingá, Maringá, PR, Brazil.

${ }^{3}$ MSc, Assistant Professor, Universidade Estadual do Norte do Paraná, Bandeirantes, PR, Brazil.

${ }^{4}$ MSc, RN, Hospital Universitário de Londrina, Londrina, PR, Brazil.

${ }^{5} \mathrm{PhD}$, Adjunct Professor, Departamento de Estatística, Universidade Estadual de Maringá, Maringá, PR, Brazil.

${ }^{6} \mathrm{PhD}$, Associate Professor, Departamento de Enfermagem, Universidade Estadual de Maringá, Maringá, PR, Brazil.
} 


\section{Introduction}

In Brazil, the Emergency Hospital Services (EHS) have been characterised by long queues in waiting, overcrowding and significant pressure for new services ${ }^{(1-3)}$. In these services, the users and their companions (and here we add the workers) protest for the humanisation of services, intermediated by efficient communication; quanti-qualitative adaptation of health professionals and also improvement in the physical structure $^{(4)}$.

With the idea of improving the quality of services at the Brazilian Single Health System (Sistema Único de Saúde - SUS), the Brazilian Ministry for Health (MS) has reaffirmed its National Policy for Humanisation of Attention and Management at the SUS (HumanizaSUS), which includes the concept of Sheltering with Risk Classification (ACCR), which is a guideline and an interference mechanism to interfere with the work processes in $\mathrm{EHS}^{(5)}$. In this regard, Sheltering is characterised by qualified listening and also by conciliation between the needs of the user and the capacity of the service in responding to the demand, with a view to the qualification of attention and assignment of responsibility in relation to the secure forwarding to another service. The system of Risk Classification involves the agility of treatment through the application of a protocol which establishes the degree of user need, based on complexity rather than the order of arrival(6).

For carrying out the ACCR, there are different protocols which have been idealised, validated and implemented within an international context ${ }^{(1,7-8)}$ and which are structured based on levels of classification, according to reset colours and which establish the gravity of the cases - prioritisation scale(1). In the proposal of HumanizaSuS, through a Nursing Consultation, the nurse classifies the cases based on a colour system represented as follows: red = emergency, yellow = urgency; green $=$ lesser urgency and blue = no urgency(6). $^{(6)}$

Considering the possibility of bias in application of international protocols and instruments and/or those developed in different contexts ${ }^{(8)}$, apart from the issue of high cost for acquisition, it is recommended that own institutional protocols are developed, through collective work between the subjects involved in the processes, so as to meet the local needs ${ }^{(5)}$.

In spite of different protocols for the operationalisation of ACCR in Brazilian EHSs, there is still a dearth of studies to assess the impact thereof, as also the implementation ${ }^{(9)}$. The assessment of ACCR becomes imperative when there is an intention of getting improvement of quality and security in user attention, as also the working conditions of the EHS team(10), as assessment methods are essential for the enhancement of actions, as they make the analysis of potential and weakness of aspects of structure, processes and results more feasible.

In Brazil, the Ministry of Health since $2004^{(6)}$ has recommended the use of the ACCR guidelines for service at EHSs, but many institutions still operate according to the traditional model, based on the order of arrival(1), whether though the lack of appropriate physical spaces, shortage of human resources in quantity and quality, among other difficulties.

The apparent low proportion of EHSs following the guidelines of the Ministry of Health (MS) could be one of the factors responsible for the scarcity of publications about the implementation and/or assessment of the ACCR. Together with this, we also see the lack of instruments validated for this purpose, further limiting the field of activity of researchers interested in this issue.

Considering the lack of instruments to assess the ACCR, published on the most important databases and virtual libraries, available online (Virtual Health Library, known locally as the Biblioteca Virtual de Saúde - BVS); Scientific Electronic Library Online digital library (Scielo); Nursing Database (Base de Dados de Enfermagem - BDENF); Database of Latin American and Caribbean Literature and Health Sciences (Bases de Dados da Literatura Latino-Americana e do Caribe em Ciências da Saúde - LILACS), in 2011 Belluci Jr. prepared a questionnaire based on the Donebedian dimensions of health assessment (Structure, Process and Result) and also proceeded with the validation of the content and the face, obtaining a satisfactory rate of agreement between assessor and also a reliability rate of more than $0.8(80 \%)$ for the three dimensions mentioned ${ }^{(9)}$.

Considering the gap in the knowledge about ACCR assessment, this study is justified because the results may subsidise future actions, whether in the general scope of Health Services or specifically for Nursing, aimed at the (re)planning and monitoring of the attention process in EHS, as well as helping towards the enhancement of the environment and also the work processes of the places investigated.

The guiding question for this study is that of knowing how the EHS workers in two teaching hospitals assess the development of ACCR. To answer this question, the following aim was established: Assess, from the worker's 
standpoint, the structure, the process and the results of two EHSs, inserted in teaching hospitals, which use the ACCR guideline.

\section{Method}

Quantitative, descriptive, exploratory and prospective study, carried out in two public teaching hospitals in the state of Paraná, known as Hospital A and Hospital B. The data was collected between August and November 2011, after the project was approved by the Ethics Committee for Research involving Human Subjects (COPEP) of the State University of Maringá, under No. 325/2011 and the Research Ethics Committee (REC) of the State University of Londrina under No. $11550 / 2011$. All the subjects have signed an Informed Consent Form - ICF.

Hospital A is a reference in the State for service to high-complexity patients, and is part of the State System for Urgent and Emergency Treatment as a type III hospital, and is open round the clock, having introduced the ACCR in July 2007. The EHS of this institution holds 48 beds for short terminal stays, but has an average of 96 patients in the segment every day, with an average of 46,000 services/year(11).

Hospital B is also a reference in high-complexity treatment of cases of trauma and has its doors open round the clock. The EHS here has 30 beds for short hospital stays, but handles over 90 patients a day, with total service of 47,000 patients per year, having installed the ACCR in December 2010(12).

Stratified random sampling, of proportional allocation, was then carried out, with the number of professionals of both EHSs being stratified by professional category. The subjects were selected based on a numbered list with the names of all servers, by professional category and in alphabetical order. On refusal, or when the subject is not found after three tries, the following name is chosen and so on successively, until the end of the list or until at least $60 \%$ of all workers in each category are included. To establish this percentage, prior to the collection of data, we considered a margin of $40 \%$ for losses through rejections $(20 \%)$, planned and unplanned absenteeism (20\%), for the two EHSs.

As criteria for inclusion we considered: professionals who were directly active in the EHS (Nurses, Medical Staff, Reception, Security, Hospital Hygiene and Social Assistance) and also the time working in the EHS, of three months or more.
Based on the type of sampling and the announced criteria, the sample comprised 216 professionals, of which 122 (56.5\%) in SHE A and 94 (43.5\%) of SHE B.

For data collection, the questionnaire "Instrument for Assessment of ACCR" was used; it consisted of two parts: Part I, for collection of social and demographic data of the subjects, and Part II, which is subdivided into the different dimensions of the Donabedian triad for health assessment, where items 1 to 7 refer to Structure; 8 to 14 to the Process, and 15 to 21 . The answers were presented as a five-point Likert scale: Totally Disagree; Disagree; Neither Agree nor Disagree; Agree; Totally Agree $^{(9)}$. Considering the minimum value of each item, the minimum point score for each dimension is 7 points and the maximum is 35 , with a total spread of 28 .

For the classification of data, for each dimension, we used the Table of Categories and Scores, as proposed in the document: "Instrument of Assessment for Centres and Health Centres"(13), as shown in figure 1 below.

\begin{tabular}{|c|c|c|}
\hline Point Score & Percentage & Classification \\
\hline 7 to 17.4 & 0 to 49.9 & Insufficient \\
\hline 17.5 to 26.1 & 50 to 74.9 & Precarious \\
\hline 26.2 to 31.4 & 75 to 89.9 & Satisfactory \\
\hline 31.5 to 35 & 90 to 100 & Excellent \\
\hline
\end{tabular}

Source: Adapted from the Brazilian Ministry for Health (BR) ${ }^{(13)}$

Figure 1 - ACCR Classification Scores by Donabedian dimensions, Maringá, Paraná, Brazil, 2012

The data was tabulated using electronic spreadsheets of Microsoft ${ }^{\circledR}$ Excel for Windows 7.0 and then simple statistical analysis (frequencies and percentages) and descriptive statistics (variation, minimum, maximum, mean, median and standard deviation - SD) in the programme known as EpiInfo 3.5.3.

\section{Results}

The social and demographic distribution of the subjects ( $n=216$ ) showed itself to have the following characteristics: Hospital $A$ - mean age of 41.4 years $(\mathrm{SD}=10.7$; median 40.0; minimum 22.0; maximum $67.0) ; 78$ (63.9\%) female; 79 (64.7\%) either married or in a stable relationship; $24(19.7 \%)$ single; 16 (13.1\%) separated and $3(2.5 \%)$ widowed. In relation to educational level, 71 (58.2\%) had completed high school education, with an average time of activity in the EHS at the institution of 8.6 years (SD 8.9; median 4.5; 
minimum 0.25 and maximum 35). Hospital $B$ - mean age of 40.5 years (SD 10.9; median 41.0 ; minimum 23.0; maximum 67.0), 60 (63.8\%) female; 55 (59.8\%) married or in a stable relationship; 21 (22.8\%) single; 15 (16.3\%) separated; 1 (1.1\%) widowed and two who did not answer. Most of the subjects, 40 $(42.6 \%)$, had specialisation courses at graduate level, and this group had an average of 8.6 years at the EHS of the institution (SD 7.6; median 5.0; minimum 0.25 , maximum 25).

Table 1 - Distribution of subjects in relation to the variable of professional category/post. Maringá, PR, Brazil, 2012

\begin{tabular}{|c|c|c|c|c|c|c|}
\hline \multirow{2}{*}{$\begin{array}{c}\text { Professional Category/ } \\
\text { Function* }\end{array}$} & \multicolumn{2}{|c|}{ Hospital A } & \multicolumn{2}{|c|}{ Hospital B } & \multicolumn{2}{|c|}{ Total } \\
\hline & $\mathrm{n}$ & $\%$ & $\mathbf{n}$ & $\%$ & $\mathbf{n}$ & $\%$ \\
\hline Administrative Agent & 10 & 8.2 & 06 & 6.4 & 16 & 7.4 \\
\hline Operational Agent & 11 & 9.0 & 15 & 16.0 & 26 & 12.0 \\
\hline Security Agent & 02 & 1.6 & 06 & 6.4 & 08 & 3.7 \\
\hline Social Assistant & 01 & 0.8 & 02 & 2.1 & 03 & 1.4 \\
\hline Nursing Assistant or Technician & 75 & 61.5 & 26 & 27.7 & 101 & 46.7 \\
\hline Nurse & 09 & 7.4 & 10 & 10.6 & 19 & 8.8 \\
\hline Doctor & 14 & 11.5 & 29 & 30.8 & 43 & 20.0 \\
\hline Total & 122 & 100 & 94 & 100 & 216 & 100 \\
\hline
\end{tabular}

*Professional Category/Function: Administrative Agent = Administration Assistants and Technicians, Receptionists and Switchboard Operators; Operational Agent $=$ Caretakers and Drivers; Security Agent $=$ Security Guards and Front Door Staff; Doctor $=$ Teachers and Residents

In relation to the Average Point Score, all the dimensions of the ACCR were classified as Precarious (17.5 to 26.1 points), as we can see in Table 2 .

Table 2 - Average Point Score, by Donabedian Dimension, by service. Maringá, Paraná, Brazil, 2012

\begin{tabular}{cccccc}
\hline & Mean & SD & Median & Minimum & Maximum \\
\hline $\begin{array}{c}\text { Structure } \\
\text { EHS A }\end{array}$ & 21.9 & 4.6 & 22.0 & 10.0 & 35.0 \\
EHS B & 19.3 & 4.2 & 19.0 & 9.0 & 28.0 \\
Process & & & & & \\
EHS A & 21.8 & 4.3 & 21.5 & 13.0 & 35.0 \\
EHS B & 21,0 & 3.4 & 21.0 & 13.0 & 30.0 \\
Result & & & & & \\
EHS A & 23.7 & 4.4 & 24.0 & 13.0 & 34.0 \\
EHS B & 23.1 & 3.9 & 23.0 & 9.0 & 31.0 \\
\hline
\end{tabular}

In Table 3 there is the number and the percentage of subjects who have checked the EHS classification in each dimension.

For the treatment of the data, in relation to the opinion of the subjects about the Donabedian dimensions of ACCR, the answers of Disagree and Totally Disagree were considered Disagreements, while those considered Agree and Totally Agree were considered Agreements. Those shown as Neither Agree nor Disagree were not considered in the discussion, as they do not represent the greatest percentage of each item of assessment.

Table 3 - Number and Percentage of Classifications by Donabedian Dimension, Maringá, PR, Brazil, 2012

\begin{tabular}{|c|c|c|c|c|c|c|c|c|c|}
\hline & \multirow{2}{*}{$\mathbf{n}$} & \multicolumn{2}{|c|}{ Insufficient } & \multicolumn{2}{|c|}{ Precarious } & \multicolumn{2}{|c|}{ Satisfactory } & \multicolumn{2}{|c|}{ Excellent } \\
\hline & & $n$ & $\%$ & $\mathbf{n}$ & $\%$ & $n$ & $\%$ & $\mathrm{n}$ & $\%$ \\
\hline \multicolumn{10}{|l|}{ Structure } \\
\hline \multicolumn{10}{|c|}{ Institution } \\
\hline EHS A & 122 & 20 & 16.4 & 87 & 71.3 & 10 & 8.2 & 05 & 4.1 \\
\hline EHS B & 94 & 30 & 31.9 & 60 & 63.8 & 04 & 4.3 & - & - \\
\hline Total & 216 & 50 & 23.1 & 147 & 68.1 & 14 & 6.5 & 05 & 2.3 \\
\hline
\end{tabular}


Table 3 - (continuation)

\begin{tabular}{|c|c|c|c|c|c|c|c|c|c|}
\hline & \multirow{2}{*}{$\mathbf{n}$} & \multicolumn{2}{|c|}{ Insufficient } & \multicolumn{2}{|c|}{ Precarious } & \multicolumn{2}{|c|}{ Satisfactory } & \multicolumn{2}{|c|}{ Excellent } \\
\hline & & $\mathbf{n}$ & $\%$ & $\mathbf{n}$ & $\%$ & $\mathbf{n}$ & $\%$ & $\mathbf{n}$ & $\%$ \\
\hline \multicolumn{10}{|l|}{ Process } \\
\hline \multicolumn{10}{|c|}{ Institution } \\
\hline EHS A & 122 & 14 & 11.5 & 92 & 75.4 & 11 & 9.0 & 05 & 4.1 \\
\hline EHS B & 94 & 12 & 12.8 & 74 & 78.7 & 08 & 8.5 & - & - \\
\hline Total & 216 & 26 & 12.0 & 166 & 76.9 & 19 & 8.8 & 05 & 2.3 \\
\hline \multicolumn{10}{|l|}{ Result } \\
\hline \multicolumn{10}{|c|}{ Institution } \\
\hline EHS A & 122 & 07 & 5.7 & 86 & 70.5 & 21 & 17.2 & 08 & 6.6 \\
\hline EHS B & 94 & 08 & 8.5 & 67 & 71.3 & 19 & 20.2 & - & - \\
\hline Total & 216 & 15 & 7.0 & 153 & 70.8 & 40 & 18.5 & 08 & 3.7 \\
\hline
\end{tabular}

\section{Discussion}

In relation to the size of the sample, among the workforce of the technical administration staff participating in the study of EHS A $(n=122)$ there were $77 \%$ of the Security Agents, Operational and Administrative Staff; $100 \%$ of the Social Assistants; $79 \%$ of the Nursing Assistants and Technicians; 64\% of Nurses and $52 \%$ of Medical Staff. In the case of EHS B ( $n=94)$, there was the participation of $34 \%$ of Security Agents, Operational and Administrative Staff; $100 \%$ of Social Assistants; $65 \%$ of Nursing Assistants and Technicians; $37 \%$ of Nurses and $23 \%$ of Medical Staff. The fact that the level of $60 \%$ was not reached by some categories was mainly due to the level of refusals (>20\%), and absences (holidays or leave) where there has been no localisation after three tries.

Based on the analysis of social and demographic data of all the participants in the research, we see that most of the people considered in EHS A belong to some professional category of the Nursing segment and represents a percentage of $68.9 \%$, while in the case of SHE B this value is $38.3 \%$. The mean age ranged between 40 and 41 years old, with data being similar for both institutions (EHS A - 41.4; EHS B - 40.5). In both groups there was a prevalence of females (EHS A - 63.9\%; EHS - 63.8\%), married and/or in stable relationships (EHS A - 64.7\%; EHS B - 59.8\%). These findings confirm the studies on the profile of the profession(14-15), but one fact that draws attention is that in Hospital B the medical profession is the majority among all professional groups, with $29(30.8 \%)$ of subjects.

Here we must mention the quantitative difference between professional categories in the two EHSs, as in Hospital B, including teaching staff, duty professionals and also residents, there are more doctors (126) than in Hospital A (27), which is considerably bigger in terms of structure, but equitative in terms of productivity. The same applies to the nurses, as in A there were 14 professionals compared with 27 in $B$. The larger number of doctors in B probably ensured a greater participation of this professional category among the respondents of the study (30.8\%) and this could have affected the scores for the institution (Table 1).

In relation to schooling, in EHS A, 71 (58.2\%) subjects had complete high school education, while in $B$ $40(42.6 \%)$ had graduate level schooling. This last piece of data, which could be related to the fact that most of the respondents are doctors (29-30.8\%) and nurses $(10-10.6 \%)$ and, also considering the ever-growing requirements set by the labour market, it has been common within the routine of the practice to observe specialisation and skills training of the professionals at University level.

The variable of time spent at the EHS showed a profile of professionals with experience in the area (both EHSs had a mean of 8.6 years), which participated in the process of implementation of the ACCR at the EHS where they are active. This is important because, among the values that guide Humanizasus there is that of corresponsibilisation, value of the subjects, protagonism and group participation ${ }^{(5-6)}$.

In the assessment of each dimension (Table 2 and Table 3), the point score obtained characterised the ACCR in both EHSs as Precarious. However, it becomes necessary to make some comments about some points of agreement and disagreement as observed in both locations, according to the number of subjects and percentage.

Among the aspects in agreement, regarding Structure in EHS A, we could highlight the humane and welcoming environment $(60=49 \%)$; privacy for the user 
(58-47\%) and welcoming of the companion (67=55\%), which were also mentioned, in the same sequence, in the case of EHS B, by $53(57 \%), 42(45 \%)$ and 67 (71\%) professionals, respectively.

In the Process dimension, concerning EHS A, the points of agreement were: promotion of the security and comfort of the user $(65=53 \%)$; welcoming and classification of all patients $(98=80 \%)$; knowledge, on the part of the servers, of the ACCR protocol $(56=46 \%)$ and training for welcoming and rotative services (53=43\%).

In the Result dimension, there was agreement in EHS A about primary service - Risk Classification by the nurse, according to seriousness of the case $(88=73 \%)$; integration between the teams $(71=58 \%)$ and the awareness of the family member about waiting time $(93=75 \%)$. In EHS B, this happened with seriousness $(74=79 \%)$, waiting time $(53=56 \%)$ and humanisation of all phases of ACCR $(43=46 \%)$.

Based on the percentages as here presented for the agreeing aspects, it is possible to observe that in the case of the two EHSs the implementation of the ACCR has motivated the readaptation of the physical structure and also of the work process, promoting greater humanisation, training of the teams and also access to the whole demand, in line with the guidelines established in the proposal made by HumanizaSUS ${ }^{(1,5-6)}$, however, based on the reference scale as adopted, these values still ensure a classification of Precarious (50 to $74.9 \%$ ) to both, showing the need for greater investments in these aspects. Despite the favourable situations confirmed, it is not possible to say whether the expansion of access has improved the quality of the service, without overloading these teams, and this is surely an object that can and should be investigated.

In relation to the points of disagreement that have contributed towards the classification of the EHSs as Precarious, in relation to Structure we see that EHS A had greater disagreement in the execution of meetings and regular training $(50=41 \%)$ and communication between the members of the multiprofessional team $(74=61 \%)$; In the case of EHS B, the highlight was the item involving comfort of the physical structure $(53=56 \%)$ and signalling for the guidance of the user $(40=42 \%)$. Here we must also stress that, even though previously the results for EHS $B$ had suggested a welcoming and human environment ensuring privacy, this structure as created was not considered comfortable and sufficiently signposted to ensure the secure movement of the user between the different environments.
In relation to the Process, EHS A showed disagreement about the concession of discussion space on the part of the management $(56=46 \%)$ and reassessment of the ACCR Flow Chart with the team $(55=45 \%)$. This was also highlighted in EHS B, by $44(47 \%)$ and $48(51 \%)$ of the subjects interviewed, respectively.

We also see that the physical structure, especially in the case of EHS B, needs readaptations, but one thing that calls attention in both Services is the presence of problems related to communications between the members of the teams, represented by the lack of democratic space for discussion, reflection and problematisation, which limit the success of the $\mathrm{ACCR}^{(5-6)}$.

The management system still in use in most Brazilian hospitals is the functional model, which is characterised by vertical and formal structures; however, in the contemporary world we see the need for more flexible structures that promote management autonomy, with organisational decentralisation, so that all workers may participate in decision-making processes as affect their work(16), resulting in a greater involvement, commitment and responsibilisation, these requirements being essential, in this case, for the success of the ACCR guideline.

For the Results dimension in EHS A there was disagreement about the prioritisation of service after Risk Classification, for seriously ill patients $(75=61 \%)$ which was also seen in EHS B $(66=77 \%)$. In addition, EHS B showed disagreement about the forwarding of low complexity cases to the basic network $(51=54 \%)$ and the management taking on the doubts of the ACCR (31-33\%).

About the priority given to seriously ill patients, in a context of overcrowding, where there is a mix of patients who are haemodynamically unstable, in urgency and emergency situations, with patients of low complexity ${ }^{(3,8,17-18)}$, there is a difficulty to visualise and prioritise the service ${ }^{(19)}$. For this purpose, ACCR assumes the application of a protocol which establishes a need for service and also the potential of worsening for each specific case as here considered ${ }^{(6)}$.

In relation to the treatment given to the parcel of the user universe with non-urgent cases who seek emergency services, it must be stressed that the basic health network must be able to deal with this demand, without delay ${ }^{(1)}$; otherwise, the main aims of the ACCR shall not have been entirely achieved.

To reduce the aforementioned situation, there is a need for public policy to give sustenance to the practice 
of reference and counter-reference, as the systematised establishment of articulations with such services would guarantee the efficiency of the transfers, which is an essential condition for the success of the $\operatorname{ACCR}^{(6,20)}$.

It must also be considered that the shortcomings in the reference and counter-reference system, apart from overloading the EHS, may also lead to superficial and hardly resolutive service to the patients considered as being less serious cases ${ }^{(17)}$ which, surely, brings risks to the population at large. Together with this issue, there is also the cultural view that the EHS is an option for the lack of support to basic health care, characterised by the delays in booking appointments and lack of specialist physicians $^{(17,19)}$ meaning that the population prefers to wait for hours but with guaranteed treatment, thus overloading the $\mathrm{EHSs}^{(3)}$.

In this kind of environment, with overcrowding, work overload and stress, interpersonal relations are seriously jeopardised(3) and the very process of work becomes arduous, insecure and hardly resolutive, demanded perhaps, hence the urgency of real participation in the ACCR philosophy, with the involvement and commitment to health care.

We also mention that the opinions of the people investigated were more or less split in relation to some of the items here addressed, such as: reassessment of the user waiting to be seen to by the nurse at EHS A (Agreement 51=42\%; Disagreement 48=39\%); multiprofissional integration at EHS B (Agreement $35=37 \%$; Disagreement 33-36\%), and humanisation of all the ACCR phases at EHS A (Agreement 47=39\%; Disagreement $48=39 \%$ ).

In relation to the reassessment of the user waiting for service by the nurse at SHE A, we have seen that, with the exception of the social assistant, all the other professions that participated in the study have shown disagreeing opinions about this issue. This item of data is a cause for concern because it shows a need for future investigations about the activities of this nurse in the ACCR. After all, the reassessment of users, after welcoming and classification, is essential for the quality and the security of attention, as the general health of the patient can get worse after initial assessment ${ }^{(8,21)}$ or there could also be exacerbation of signs and symptoms which were initially not observed by the Risk Classification $^{(21)}$.

Regarding multiprofissional integration, this is recognised as an essential condition for the success of $\mathrm{ACCR}^{(19)}$, as multiprofissional workshops are recommended by the Brazilian Ministry for Health
(MS), for the discussion and construction of actions and protocols ${ }^{(6)}$, meaning that the managers of EHS B need to intervene to solve this problem.

A meeting of the multi-professional team to discuss and rethink the environment and work processes, collectively creating suggestions for the optimisation of the organisation, is one way of exercising a democratic style of management, which is an essential model nowadays ${ }^{(16)}$.

In relation to the humanisation of all the phases of ACCR, we consider that this is the essence of the guideline and its effectivation does not require much investment, as this can be favoured by qualified listening(8,22-23), and by the supply of clear information, including the expected waiting time; prioritisation of seriously ill patients; emotional support for the user and his or her companion ${ }^{(1)}$.

ACCR was idealised to be an effective and efficient tool in the search for improvement of quality of service in EHS and, with Nursing being an essential element in the health team and with the Nurse being the executor of the classification protocol, this professional category is the main party responsible for the good progress of the process at hand ${ }^{(23)}$. This means associated to the development of actions towards professional valuation which awaken the feelings of correspondibility of the worker through the results concerning health care ${ }^{(17)}$; it is also necessary that the Nursing present in an EHS is always skilled and valued.

For the success of the ACCR, such as a proposed change in the models for health care and management of health practices ${ }^{(6)}$, there is an urgent need for a think on the part of the leading players in this process (managers, professionals and users). It is also important to analyse if in practice this guideline has really carried out its role as a trigger for the transformation of the work processes and also the relationships between workers and users $(3,17,22,24)$, or if it has just restricted itself to allowing service to all the spontaneous demand, more like an emergency service ${ }^{(3)}$, focused on the complaint and not guaranteeing any improvement to quality, but rather a greater productivity ${ }^{(22,24)}$.

In general, the EHS as here investigated have particularities, but both converge on the need for improvements related to the guidelines of the ACCR as practiced. In this context, the results as here presented could act as subsidies for the preparation of strategies, by managers and also by the other professionals involved, for effectivation of the ACCR using the models on which this guideline has been proposed. 


\section{Conclusion}

It was confirmed that in the EHSs investigated, the Donabedian dimensions of Structure, Process and Results were considered Precarious. Here we highlight the fact that EHS A implemented ACCR five years ago, while EHS B did so only two years ago, both therefore being recent and, therefore, needing (re)assessment and readaptations.

Even though the EHS investigated have shown some favourable results such as: a warming and humane environment, privacy, security and comfort for the users, welcoming of the companion and welcome and classification of all the patients, also identified problems, mainly in relation to the reference and counter-reference system, prioritisation of seriously ill patients in service after Risk Classification, communication between the members of the professional team, and reassessment of the proposal as a whole by the team.

As a limitation on the study, we consider the reduced size of the samples in the case of some professional categories, caused by rejections or by the non-localisation of subjects in three distinct attempts, especially in the medical class and also professionals who do not see themselves as members of the team active at the ACCR, like the case of security staff and also the door staff.

We recommend the execution of more research with bigger samples, with aims directed to awareness of the opinions of professional people from other EHSs of the country, which have implemented the ACCR, as also the respective users.

We therefore reach the conclusion that the workers in the EHSs investigated, based on the reference adopted, assess the ACCR as Precarious because, in spite of the investment initiatives on the part of the two EHSs, in improvements to structure and also to the system of work and assistance, there is still a lot to be done to improve the conditions of comfort, interpersonal communications, continuous skills training, continuous reassessment of the protocol and also, just as important, the structuring and integration of the hospitals with the basic health care network.

\section{Aknowledgments}

I would like to thank the students of the graduate course in Nursing at the State University of Londrina - Andréa Moreira da Silva, Anna Lúcia Darcin Rigo, Anne Caroline Correia S. de Oliveira, Barbara Duarte Neris, Bianca Carolina Zanardi Porto, Carine Gasparoto de Lima, Elizabete Rosane Palharini, Franciele Dinis
Ribeiro, Francieli Sayuri, Márcia Aparecida dos Santos Silva, Thaiara Maestro Calderon e Vanessa Monique Luis Costa - who participated in the data collection phase, as trainees of the Quality Control Service of the Nursing Assistance Division of the University Hospital of the State University of Londrina, Paraná, Brazil.

\section{References}

1. Albino RM, Grosseman S, Riggembach V. Classificação de Risco: uma necessidade inadiável em um serviço de emergência de qualidade. ACM: Arq Catarinenses Med. 2007; 36(4):70-5.

2. Bittencourt RJ, Hortale VA. Intervenções para solucionar a superlotação nos serviços de emergência hospitalar: uma revisão sistemática. [Revisão]. Cad Saúde Pública. 2009;25(7):1439-54.

3. Zanelatto DM, Pai DD. Práticas de acolhimento no serviço de emergência: a perspectiva dos profissionais de enfermagem. Cienc Cuid Saúde. 2010; 9(2):358-65. 4. Andrade LM, Martins EC, Caetano JA, Soares E, Beserra EP. Atendimento humanizado nos serviços de emergência hospitalar na percepção do acompanhante. Rev Eletr Enferm. [Internet]. 2009 [acesso 20 out 2012];11(1):151-7. Disponível em: http://www.fen. ufg.br/revista/v11/n1/pdf/v11n1a19.pdf

5. Ministério da Saúde (BR). Acolhimento e Classificação de Risco nos serviços de Urgência. Brasília (DF): Ministério da Saúde; 2009.

6. Ministério da Saúde (BR). HumanizaSUS: acolhimento com avaliação e classificação de risco: um paradigma estético no fazer saúde. Brasília (DF): Ministério da Saúde; 2004.

7. Casares NG, Lores FJM, Guzmán CU, Juanes SA. Protocolo de triage o recepción, acogida y clasificación (RAC) de enfermería en urgencias del Hospital Do Salnés. Enferurg.com [Internet]. 2005 [acesso 17 mar 2012]. Disponível em: http://www.enferurg.com/ articulos/protocolorac.htm

8. Souza CC, Toledo AD, Tadeu LFR, Chianca TCM. Risk classification in an emergency room: agreement level between a Brazilian institutional and the Manchester Protocol. Rev. Latino-Am. Enfermagem. 2011;19(1):26-33.

9. Bellucci JA Jr, Matsuda LM. Construção e validação de instrumento para avaliação do Acolhimento com Classificação de Risco. Rev Bras Enferm. [Internet]. 2012; [acesso 8 maio 2013] ;65(5):751-7. Disponível em: http://www.scielo.br/scielo.php?pid=S0034$71672012000500006 \&$ script $=$ sci_arttext 
10. Luz PL. Research and teaching: essential components of a university hospital. Arq Bras Cardiol. [Internet]. 2007 [acesso 5 mar 2012];88(3):371-2. Disponível em: http://www.scielo.br/scielo.php?script =sci_arttext\&pid=S0066-782X2007000300019\&Ing=en \&nrm=iso\&tlng=en

11. Universidade Estadual de Londrina. Hospital Universitário Regional do Norte do Paraná (BR). Seção de Estatística. Movimento de pacientes no ano de 2011: comparativo 2002 - 2011. Londrina; 2012. 40 p. Relatório Anual.

12. Hospital Universitário de Maringá (BR). História do hospital. [internet]. 2012 [acesso 26 julho 2012]. Disponível em: http://www.hum.uem.br/?pg=ohospital 13. Ministério da Saúde (BR). Instrumento de avaliação para centros e postos de saúde. Brasília (DF): Ministério da Saúde; 1985.

14. Carvalho G, Lopes S. Satisfação profissional do enfermeiro em uma unidade de emergência de hospital geral. Arq Ciênc Saúde. 2006;13(4):215-9.

15. Li J, Lambert VA. Job satisfaction among intensive care nurses from the People's Republic of China. Int Nurs Rev. 2008;55(2):34-9.

16. Bernardes A, Cummings G, Evora YDM, Gabriel S. Framing the difficulties resulting from implementing a Participatory Management Model in a public hospital. Rev. Latino-Am. Enfermagem. 2012;20(6):1142-51.

17. Nascimento ERP, Hilsendeger BR, Neth C, Belaver GM, Bertoncello KCG. Classificação de risco na emergência: avaliação da equipe de enfermagem. Rev Enferm UERJ. 2011;9(1):84-8.

18. Belluci JA Jr, Matsuda LM. Implantação do sistema acolhimento com classificação e Avaliação de risco e uso do fluxograma analisador. Texto Contexto - Enferm. 2012;21(1):217-25.

19. Souza RS, Bastos MAR. Acolhimento com classificação de risco: o processo vivenciado por profissional enfermeiro. REME. 2008;12(4):581-6.

20. Fracolli LA, Zoboli ELCP. Descrição e análise do acolhimento: uma contribuição para o programa de saúde da família. Rev Esc Enfem USP. 2004;38(2):143-51.

21. Cooke MW, Jinks S. Does the Manchester triage system detect the critically ill? J Accid Emerg Med. [Internet].1999 [acesso 17 julho 2012];16(3):17981. Disponível em: http://www.ncbi.nlm.nih.gov/pmc/ articles/PMC1343329/pdf/jaccidem00030-0017.pdf

22. Carvalho CAP, Marsicano JA, Carvalho FS, SalesPeres A, Bastos JRM, Sales-Peres SHC. Acolhimento aos usuários: uma revisão sistemática do atendimento no
Sistema Único de Saúde. [Revisão]. Arq Ciênc Saúde [Internet]. 2008 [acesso 25 ago 2012];15(2):93-5. Disponível em: http://www.cienciasdasaude.famerp.br/ racs_ol/vol-15-2/iD\%20253.pdf

23. Bellucci JÁ Jr, Matsuda LM. O enfermeiro no gerenciamento à qualidade em Serviço Hospitalar de Emergência: revisão integrativa da literatura. [Revisão]. Rev. Gaúcha Enferm. 2011;32(4):797-806.

24. Takemoto MLS, Silva EM. Acolhimento e transformações no processo de trabalho de enfermagem em unidades básicas de saúde de Campinas, São Paulo, Brasil. Cad Saúde Pública. 2007:23(2):331-40. 